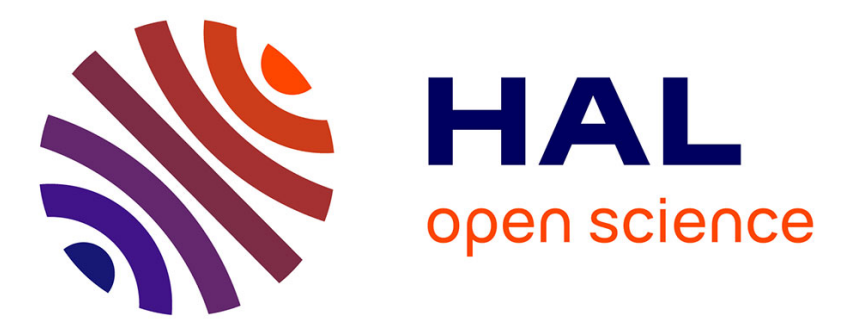

\title{
The Leishmania infantum cytosolic SIR2 related protein 1 (LiSIR2RP1) is an NAD+-dependent deacetylase and ADP-ribosyltransferase
}

Joana Tavares, Ali Ouaissi, Nuno Santarém, Denis Sereno, Baptiste Vergnes, Paula Sampaio, Anabela Cordeiro-Da-Silva

\section{To cite this version:}

Joana Tavares, Ali Ouaissi, Nuno Santarém, Denis Sereno, Baptiste Vergnes, et al.. The Leishmania infantum cytosolic SIR2 related protein 1 (LiSIR2RP1) is an NAD+-dependent deacetylase and ADPribosyltransferase. Biochemical Journal, 2008, 415 (3), pp.377-386. 10.1042/BJ20080666 . hal00479004

\section{HAL Id: hal-00479004 \\ https://hal.science/hal-00479004}

Submitted on 30 Apr 2010

HAL is a multi-disciplinary open access archive for the deposit and dissemination of scientific research documents, whether they are published or not. The documents may come from teaching and research institutions in France or abroad, or from public or private research centers.
L'archive ouverte pluridisciplinaire HAL, est destinée au dépôt et à la diffusion de documents scientifiques de niveau recherche, publiés ou non, émanant des établissements d'enseignement et de recherche français ou étrangers, des laboratoires publics ou privés. 
The Leishmania infantum cytosolic SIR2 related protein 1 (LiSIR2RP1) is an $\mathrm{NAD}^{+}$-dependent deacetylase and ADP-ribosyltransferase

Joana TAVARES ${ }^{*} \S$, Ali OUAISSI ${ }^{*}{ }^{*}$, Nuno SANTARÉM ${ }^{* \uparrow}$, Denis SERENO ${ }^{\S}$, Baptiste VERGNES ${ }^{\S}$, Paula SAMPAIO* and Anabela CORDEIRO-DA-SILVA ${ }^{* * 12}$

* IBMC - Instituto de Biologia Molecular e Celular, Universidade do Porto, Rua do Campo Alegre, 823, 4150-180 Porto, Portugal, ${ }^{\dagger}$ Laboratório de Bioquímica, Faculdade de Farmácia da Universidade do Porto, R. Aníbal Cunha n. ${ }^{\circ}$ 164, 4050-047 Porto, Portugal, ${ }^{\sharp}$ INSERM, CNRS, UMR 5235, Université de Montpellier 2, Bât 24 - CC 107 , Pl. Eugène Bataillon, 34095 Montpellier Cx 5, France and ${ }^{\S}$ Centre IRD de Montpellier, 911 avenue Agropolis, 34394 Montpellier, France.

${ }^{1}$ Both authors have supervised the implementation of the work.

${ }^{2}$ To whom correspondence should be addressed (e-mail: cordeiro@ibmc.up.pt). 
Short (page heading) title: LiSIR2RP1 deacetylates and ADP-ribosylates $\alpha$-tubulin

Keywords: Parasites, LiSIR2RP1, $\alpha$-tubulin, ADP-ribosyltransferase, NAD ${ }^{+}$-dependent deacetylase, cytoskeleton.

Abbreviations used:

FBS, Foetal bovine serum; IPTG, Isopropyl- $\beta$-D-thiogalactopyranoside; MAA, Medium for axenic amastigotes; OAADPr, O-acetyl-ADP-ribose; RT, Room temperature;SIR2, Silent Information Regulator 2; TCA, trichloroacetic acid; TSA, trichostatin A; DTT, dithiothreitol; PI, propidium idodide; wt, wild type; 


\section{Synopsis}

Proteins of the SIR2 family are characterized by a conserved catalytic domain that exerts unique $\mathrm{NAD}^{+}$-dependent deacetylase activity on histone and various other cellular substrates. Previous reports from our team have identified a Leishmania infantum gene encoding a cytosolic protein termed LiSIR2RP1 that belongs to the SIR2 family. Targeted disruption of one LiSIR2RP1 gene allele led to decreased amastigote virulence, in vitro as well as in vivo. In the present study, attempts were made for the first time to explore and characterize the LiSIR2RP1 enzymatic functions. The LiSIR2RP1 exhibited robust $\mathrm{NAD}^{+}$-dependent deacetylase and ADP-ribosyltransferase activities. Moreover, LiSIR2RP1 is capable of deacetylating tubulin, either in dimers or, when present, in taxol-stabilized microtubules or in promastigote and amastigote extracts. Furthermore, the immunostaining of parasites revealed a partial co-localization of $\alpha$-tubulin and LiSIR2RP1 with punctuate labelling, seen on the periphery of both promastigote and amastigote stages. Isolated parasite cytoskeleton reacted with antibodies showed that part of LiSIR2RP1 is associated to the cytoskeleton network of both promastigote and amastigote forms. Moreover, the Western blot analysis of the detergent's soluble and insoluble fractions of promastigote and amastigote forms revealed the presence of $\alpha$-tubulin in the insoluble fraction, and the LiSIR2RP1 distributed in both soluble and insoluble fractions of promastigotes as well as amastigotes. Collectively, our results demonstrate that LiSIR2RP1 is an NAD ${ }^{+}$dependent deacetylase that also exerts an ADP-ribosyltransferase activity. The fact that tubulin could be among the targets of LiSIR2RP1 may have significant implications during the remodelling of the parasite's morphology and its interaction with the host cell. 


\section{INTRODUCTION}

The yeast $\underline{\text { Silent }}$ Information Regulator 2 (SIR2) protein is the founding member of a large conserved family of proteins that are present in many organisms ranging from bacteria to humans [1]. This protein is an $\mathrm{NAD}^{+}$-dependent histone deacetylase that modulates the chromatin structure, and silences the transcription at the level of the silent mating type loci, telomeres and ribosomal DNA [2-4]. In addition to epigenetic silencing, the yeast SIR2 also has a role in DNA repair, recombination and DNA replication [5]. The first evidence that the SIR2 proteins could be involved in functions other than transcriptional silencing came from the presence of the Leishmania major SIR2 related protein in cytoplasmic granules [6]. Seven SIR2 genes were identified in humans, and the proteins classified as Sirtuins (SIRT1-7) present several subcellular localizations $[7,8]$. However, not all of the sirtuin family members seem to be active deacetylases $[9,10]$. SIRT1 is localized in the nucleus and deacetylates the histones H3 and H4, p53, TAF168 and PCAF/MyoD [4, 11-14]. Despite the SIRT2's cytosolic localization and its ability to deacetylate $\alpha$-tubulin, this protein shuttles the nucleus during $\mathrm{G} 2 / \mathrm{M}$ transition and thus plays a role in the regulation of microtubule dynamics and cell cycle progression [15-17]. The SIRT3 was found in the mitochondria controlling the activity of the acetyl-CoA synthetase 2 [18]. Histone and non-histone substrates are deacetylated by sirtuins in the presence of $\mathrm{NAD}^{+}$and lead to the production of the deacetylated protein, nicotinamide and O-acetyl-ADP-ribose (OAADPr) $[19,20]$. Several questions have been raised on understanding the sirtuin's $\mathrm{NAD}^{+}$dependency, since there is no energetic reason that favours the coupling. Among the possibilities is the connection between the proteins deacetylation and the cell's metabolic status or the formation of a second messenger, OAADPr [20].

Some members of the SIR2 family, like the yeast SIR2, the human SIRT2, the mouse SIRT6, the T. brucei SIR2RP1 and the P. falciparum SIR2, exhibit ADPribosyltransferase activity [7, 21-24]. This kind of enzymatic activity was for the first time attributed to this family of proteins due to the ability of the Salmonella typhimurium SIR2 homologue, Cob B, to compensate for the loss of Cob $\mathrm{T}$ in the cobalamine biosynthesis [25].

Additionally, sirtuins, and particularly the one associated with caloric restriction regimens in several organisms like C. elegans, yeast and fly might also be involved in longevity [26-28].

The agent of leishmaniasis, the protozoan parasite Leishmania, is responsible for serious diseases characterized by diverse clinical manifestations varying from localized ulcerative skin lesions and destructive mucosal inflammation to the disseminated visceral infection also known as Kala azar. The visceral leishmaniasis caused by $L$. infantum is a serious problem throughout the Mediterranean basin, where dogs are the most important reservoirs of the parasite. A vertebrate host becomes infected by Leishmania after the bite of a sandfly (Phlebotomus and Lutzomya spp) during a blood meal, through the inoculation of infective flagellated promastigotes that invade or are phagocytosed by local or recruited host cells. In the phagolysosomes, the promastigotes will differentiate into non-flagellated amastigotes that multiply and are able to infect other adjacent or distant macrophages. The classical treatment is currently unsatisfactory due to side effects, the appearance of resistances and the need for increased efficacy in immunosuppressed patients, especially due to HIV co-infection. During the last few years, our group has been interested in the Leishmania SIR2 proteins due to the role of LiSIR2RP1 in the parasite's survival and virulence $[29,30]$.

Although few reports have disclosed the SIR2 protein function in the protozoan parasites, such as Plasmodium falciparum, whose PfSIR2, localized in the nucleus, is 
involved in var gene silencing through heterochromatin formation [31], and Trypanosoma brucei, which has a chromosome-associated $\mathrm{NAD}^{+}$-dependent deacetylase and ADP ribosyltransferase that confers resistance to DNA damage [22], little is known about the Leishmania cytosolic LiSIR2RP1 biological properties. Here, we provide molecular and biochemical evidences supporting the notion that LiSIR2RP1 is an $\mathrm{NAD}^{+}$-dependent deacetylase enzyme that may also express ADPribosyltransferase activity. In addition, we show that the protein deacetylates $\alpha$-tubulin and is partially associated with the microtubule network. Further studies on LiSIR2RP1 may provide new insights into the relationships among cytoskeleton dynamic, stage transition and parasite-host cell interaction. 


\section{EXPERIMENTAL \\ Parasites}

The L. infantum (clone MHOM/MA/67/ITMAP-263) wild type (wt) promastigotes were grown at $27^{\circ} \mathrm{C}$ in RPMI 1640 medium (Cambrex) supplemented with $10 \%$ heat inactivated foetal bovine serum (FBS-Cambrex), 2mM L-glutamine (Cambrex), 20mM Hepes (Cambrex), 100U/ml penicillin (Cambrex) and $100 \mu \mathrm{g} / \mathrm{ml}$ streptomycin (Cambrex). L. infantum axenic amastigote forms were grown at $37^{\circ} \mathrm{C}$ with $5 \% \mathrm{CO}_{2}$ in a cell free medium called MAA/20 (medium for axenic amastigotes). MAA/20 consisted of modified medium 199 (GIBCO) with Hank's balanced salt solution supplemented with $0.5 \%$ trypto-casein (Oxoid), $15 \mathrm{mM}$ D-glucose (SIGMA), 5mM glutamine (Cambrex), 4mM $\mathrm{NaHCO}_{3}$ (Sigma), $0.023 \mathrm{mM}$ bovine hemin (FLUKA), and 25mM HEPES to a pH of 5.8 and supplemented with $20 \%$ heat inactivated FBS (Cambrex). The heterozygote $\operatorname{LiSIR} 2^{+/}$derived from the wt clone was generated as previously described, and maintained in their respective selective medium [30]. The levels of LiSIR2 synthesis in LiSIR2 ${ }^{+/-}$and wt parasites were evaluated by western blotting, using an anti-LiSIR2 monoclonal antibody as described in previous reports [30].

\section{Heterologous Expression and Purification of LiSIR2RP1}

The LiSIR2RP1 encoding sequence (GenBank accession number AF487351) from $L$. infantum genomic DNA was amplified by PCR using two primers, a forward primer (5'-CAATTTGCATATGACAGCGTCTCCGAGAGCGCC A-3') and a reverse primer (5'-CCCAAGCGAATTCTCACGTCTCAT TCGGCGC-3'). The amplified product of about 1200 bp was cloned into the NdeI and EcoRI restriction sites of the prokaryotic expression vector pET28a (Novagen, Madison, WI, USA) and the fusion protein LiSIR2RP1 with an N-terminal tail of six histidines was produced in E. coli BL21 (DE3). The transformants were grown in a Luria Broth medium containing $30 \mu \mathrm{g} / \mathrm{ml} \mathrm{of}$ kanamycin, and the recombinant protein expression was induced in mid-logarithmic phase with $1 \mathrm{mM}$ of isopropyl-ß-D-thiogalactopyranoside (IPTG) for 3 hours at $37^{\circ} \mathrm{C}$. The bacterial pellet was re-suspended in a buffer containing $500 \mathrm{mM} \mathrm{NaCl}, 20 \mathrm{mM}$ Tris$\mathrm{HCl} \mathrm{pH} 7.6$ and disrupted by sonication. The clarified supernatant was applied to a NiNTA agarose column (Quiagen) and the recombinant LiSIR2RP1 protein eluted with an imidazole gradient from 25 to $1000 \mathrm{mM}$. The eluted fractions were controlled for the LiSIR2RP1 presence using an SDS-PAGE. The fractions containing the recombinant protein were pooled, applied to PD-10 columns (Amersham Pharmacia Biotech) and eluted with PBS pH 7.4.

\section{Deacetylase assay}

The $\mathrm{NAD}^{+}$-dependent deacetylase activity was evaluated by using a commercially available CycLex SIRT1/Sir2 deacetylase fluorometric assay kit (Cyclex Co., Ltd., Nagano, Japan). The enzymatic reaction containing $0.25 \mu \mathrm{g}$ of rLiSIR2RP1 was carried out in accordance with the manufacturer's instructions and monitored every 30 seconds for 1 hour. The results are expressed as the rate of reaction for the first 20 minutes, due to the linear correlation between the fluorescence and this period of time.

\section{Tubulin deacetylation assay}

The tubulin deacetylation reactions were performed using either purified tubulin (Pure, Cytoskeleton Inc, Denver, USA) or L. infantum promastigote and axenic amastigote extracts, prepared in PEM buffer (80mM PIPES pH 6.8, $1 \mathrm{mM} \mathrm{MgCl} 2,1 \mathrm{mM}$ EGTA) by sonication. In both cases, the tubulin was either left in heterodimers, or polymerized in PEM buffer in the presence of $20 \mu \mathrm{M}$ taxol (Cytoskeleton Inc, Denver, USA) and 1mM 
GTP (Cytoskeleton Inc, Denver, USA) for 45 minutes at $37^{\circ} \mathrm{C}$. The reactions were carried out in deacetylase buffer $(10 \mathrm{mM}$ Tris- $\mathrm{HCl}, \mathrm{pH} 8.0$ and $10 \mathrm{mM} \mathrm{NaCl})$, in the presence or absence of $1 \mathrm{mM} \mathrm{NAD}^{+}$with constant agitation at room temperature (RT) for 3 hours. The reactions were stopped by adding 5x Laemmli sample buffer and the proteins separated by $10 \%$ SDS-PAGE and western blotted.

\begin{abstract}
ADP-ribosylation assays
The ADP-ribosylation assays were performed according to Garcia-Salcedo et al. [22]. Briefly, the assays were carried out with $1 \mu \mathrm{g}$ of either of the following proteins: rLiSIR2RP1, recombinant human SIRT1 (rSIRT1, Cyclex kit), or with the recombinant L. infantum cytosolic peroxiredoxin (LicTXNPx), in the presence of $5 \mu \mathrm{Ci}$ of $\left[{ }^{32} \mathrm{P}\right] \mathrm{NAD}$ and $5 \mu \mathrm{g}$ of the following acceptor proteins: calf thymus histones (Sigma) or BSA (Sigma). Some assays were conducted with $0.5 \mu \mathrm{g}$ of rLiSIR2RP1 or rLicTXNPx in the presence of $2.5 \mu \mathrm{Ci}$ of $\left.{ }^{32} \mathrm{P}\right] \mathrm{NAD}$ and $1 \mu \mathrm{g}$ of pure tubulin (Cytoskeleton Inc, Denver, USA) or calf thymus histones (Sigma). The reactions were performed at RT for 2 hours in a buffer containing $150 \mathrm{mM} \mathrm{NaCl}, 10 \mathrm{mM}$ dithiothreitol (DTT), $50 \mathrm{mM}$ Tris-HCl $\mathrm{pH}$ 8.8, stopped with Laemmli loading buffer and dried in Whatman paper after electrophoresis, and exposed to a film 2 for 12 hours at $-80^{\circ} \mathrm{C}$. As for quantitative experiments, the reaction products were precipitated by $20 \%$ trichloroacetic acid (TCA), washed and counted after the addition of $200 \mu 1$ scintillation fluid.
\end{abstract}

\begin{abstract}
Antibodies
Antibodies to LiSIR2RP1 were obtained from BALB/c mouse immunization. The mouse was injected intraperitoneally with $50 \mu \mathrm{g}$ of rLiSIR2RP1 in $200 \mu 1$ of PBS three times at a 7 day interval. Two weeks after the final immunization, the serum was collected. The mouse monoclonal antibody, IIIG4, against the LmSIR2, was obtained according to Vergnes et al., 2002. Mouse monoclonal anti- $\alpha$-tubulin antibody (clone DM1A) and rabbit polyclonal anti- $\alpha$-tubulin antibody were purchased from NeoMarkers, USA. Mouse monoclonal anti-acetylated tubulin antibody (clone 6-11B-1) came from Sigma Chemical $C^{\circ}$, USA. Rabbit anti-Trypanosoma brucei RAB11 antibodies were a gift from Prof. Field, MC

\section{Cytoskeleton Preparation}

The cytoskeleton preparation was performed according to Schneider et al. [32]. Briefly, the L. infantum promastigotes and axenic amastigotes were collected and washed three times in ice-cold PBS. The parasites were resuspended at a concentration of $4 \times 10^{7}$ cells $/ \mathrm{ml}$ in a buffer containing $10 \mathrm{mM}$ MOPS, $\mathrm{pH}$ 6.9, 0.1mM EGTA, $1 \mathrm{mM} \mathrm{MgSO}_{4}$ and $0.1 \%$ Triton X-100 supplemented with protease inhibitor cocktail (Roche), and incubated on ice for 10 minutes followed by a 5 minute $3000 \mathrm{~g}$ centrifugation. The supernatant was collected and concentrated to $1 / 10$ of the initial volume, and a 0.25 volume of $4 \mathrm{x}$ Laemmli sample buffer was added. The pellet was washed once with PBS and resuspended in $1 / 20$ of the initial volume with a 1:1 mixture of PBS/Laemmli sample buffer. For immunofluorescence, the pellets were prepared as described and after being washed with PBS, they were attached to poly-L-lysine-coated slides.
\end{abstract}

\title{
Immunofluorescence assays
}

L. infantum promastigotes and axenic amastigotes were fixed with 4\% paraformaldehyde in PBS for 1 hour at RT. After several washes, the parasites were made permeable with $0.1 \%(\mathrm{v} / \mathrm{v})$ Triton X-100 in PBS and incubated for 30 minutes in PBS containing $1 \%$ bovine serum albumin (PBS-1\% BSA). Parasites were then 
incubated with primary antibodies diluted in PBS-1\% BSA for 1 hour at RT, washed several times with PBS, and then incubated for 1 hour with the Alexa Fluor labelled secondary antibodies (Molecular Probes) diluted in PBS-1\% BSA at RT. The immunofluorescence assays using Leishmania cytoskeletons were performed as described above, with the exception of the fixation process, which was done using $100 \%$ methanol at $20^{\circ} \mathrm{C}$ for 15 minutes, and the permeabilization step, which was not performed. Washed parasites or cytoskeletons were mounted in Vectashield with DAPI (Vector Laboratories, Burlingame, CA). Z-series optical sections were collected through the Zeiss Axio Imager Z1 microscope (Carl Zeiss, Oberkochen, Germany), using an AxioCam. Data stacks were deconvolved using either the Axiovision AxioVs40 V 4.2.0.0 (Carl Zeiss) or the Huygens Essential version 3.0.2p1 (Scientific Volume Imaging, Hilversrum, The Netherlands). Images were treated using Adobe Photoshop CS (Adobe Microsystems, CA). 


\section{RESULTS \\ LiSIR2RP1 is an $\mathrm{NAD}^{+}$dependent deacetylase and ADP-ribosyltransferase}

The LiSIR2RP1 gene encoding sequence was cloned in the bacterial expression vector pET28a. The fusion protein with an N-terminal tail of six histidines was purified under non-denaturing conditions, with the objective of studying its enzymatic activity. After purification and dialysis, the protein showed a good level of purity as evaluated by SDS-PAGE Coomassie blue staining (Fig. 1, panel A, lane 1). As expected, the recombinant protein was recognized by the monoclonal antibodies anti-L. major SIR2 protein (IIIG4), previously generated by our group (Fig. 1, panel A, lane 2) [29]. Moreover, the mouse polyclonal antibodies produced against the rLiSIR2RP1 recognized the parasite protein in total extracts from different parasite developmental stages (Fig 1, panel B: Pl, logarithmic phase promastigotes; Ps, stationary phase promastigotes; A, axenic amastigotes). It is well established that the proteins belonging to the SIR2 family exhibit $\mathrm{NAD}^{+}$dependent deacetylase activity due to the presence of a well conserved enzymatic core domain of $\sim 250$ amino acids $[7,8]$, and this seems also to be the case for LiSIR2RP1. Indeed, as shown in Fig 2A, LiSIR2RP1 expresses an $\mathrm{NAD}^{+}$-dependent deacetylase activity that is not inhibited by $1 \mu \mathrm{M}$ of the class I and II $\mathrm{NAD}^{+}$independent deacetylase inhibitor, trichostatin A (TSA). A dose-dependent increase of the deacetylase activity catalyzed by rLiSIR2RP1 was observed with increasing concentrations of $\mathrm{NAD}^{+}$up to $\cong 0.5 \mathrm{mM}$. However, concentrations of $\mathrm{NAD}^{+}$ higher than $1 \mathrm{mM}$ led to a reduction in the deacetylase activity (Fig 2B). This phenomenon is likely to be due to the release of nicotinamide, which in turn could inhibit the LiSIR2RP1 enzymatic activity (see below). This enzyme exhibits co-factor specificity for the oxidative form of NAD that was confirmed by the absence of deacetylase activity in the presence of the reduced form of NAD (data not shown). Nicotinamide is one of the several products originated in the deacetylation reaction catalyzed by the SIR2 family members. As shown in Fig 2C, the rLiSIR2RP1 is inhibited by nicotinamide in a dose-dependent manner, and the calculated nicotinamide concentration that inhibits $50 \%$ of the enzymatic activity $\left(\mathrm{IC}_{50}\right)$ is $39.35 \pm 5.01 \mu \mathrm{M}$. Several enzymatic reactions in the presence or absence of $50 \mu \mathrm{M}$ of nicotinamide and different $\mathrm{NAD}^{+}$concentrations were performed to determine whether $\mathrm{NAD}^{+}$and nicotinamide are competing for the same binding site. The Lineweaver-Burk plot of the data demonstrates that nicotinamide is an NAD non-competitive inhibitor (Fig 2D).

Some members of the SIR2 family can mediate the transference of the ribose 5'phosphate from nicotinic acid mononucleotide to the amino acid residues of BSA, histones or SIR2 proteins themselves [7, 21-24]. To assess whether LiSIR2RP1 is an ADP-ribosyltransferase, $\left[{ }^{32} \mathrm{P}\right] \mathrm{NAD}$ was used as a donor and BSA or calf thymus histones as acceptor proteins. A non-related Leishmania recombinant protein, rLicTXNPx1, which is produced and purified as the rLiSIR2RP1, was included as a control. The analysis of the reaction products by autoradiography revealed that LiSIR2RP1 was capable of inducing ADP-ribosylation of the histones and BSA (Fig. $3 \mathrm{~A})$. However, the label intensity was stronger when histones rather than BSA were used as acceptor proteins. Additionally, the parasite protein was subject to auto ADPribosylation when incubated with the histones. No signal was detected when the proteins were incubated with $\left[{ }^{32} \mathrm{P}\right] \mathrm{NAD}$ without an acceptor protein. A quantitative ADP-ribosyltransferase reaction catalyzed by rLiSIR2RP1 using histones as the acceptor protein was carried out to characterize the factors affecting the extent of the enzymatic reaction. Increasing the concentration of rLiSIR2RP1 (2 times) led to a decrease in the extent of the enzymatic transfer of the label, whereas a 2-time increase of histone concentration led to an enhancement of ADP-ribosyl transfer to the acceptor 
target protein (Fig. 3B). This unexpected reduction of the ribosylation reaction when adding more enzyme, might be due to some level of protein aggregation. In fact, we have experienced the purification of recombinant LiSIR2RP1 enzyme and found that after dialysis, increasing the concentration of LiSIR2RP1 may lead to the formation of some aggregates.

Given that LiSIR2RP1 is a cytosolic protein, we decided to verify whether it was capable of ADP-ribosylating tubulin. Thus, purified tubulin or calf thymus histones as a control were incubated with LiSIR2RP1 or LicTXNPx in the presence of $\left[{ }^{32} \mathrm{P}\right] \mathrm{NAD}$. The autoradiography evidenced a positive but weak labelling of tubulin and LiSIR2RP1 itself, when compared with the reaction where histones were used as substrates. Even though tubulin ADP-ribosylation is an already reported modification, this is the first evidence of such ADP-ribosylation transfer mediated by a protein belonging to the SIR2 family [33]. This modification seems to either inhibit the in vitro assembly of microtubules or induce microtubule depolymerization of assembled microtubules [33].

\section{The LiSIR2RP1 is a microtubule associated protein}

We have previously reported that both $L$. major (LmSIR2RP1) and $L$. infantum (LiSIR2RP1) are cytosolic proteins [6, 29]. A similar cytosolic localization was reported in the case of human SIRT2 (yeast SIR2 ortholog) and a human NAD ${ }^{+}$independent histone deacetylase, HDAC6, both proteins have been shown to express $\alpha$ tubulin deacetylase activity $[15,34]$. Based on these observations and on the fact that tubulin is one of the most notable cytoplasmic proteins subjected to modification by acetylation [35], we first investigated the cell distribution of LiSIR2RP1 and $\alpha$-tubulin. The immunostaining of both promastigote and amastigote forms revealed partial colocalization of $\alpha$-tubulin with LiSIR2RP1 (Fig 4A). In addition to the positive signals observed in the parasite cytoplasm, punctuate labelling could be seen on the periphery of both promastigote and amastigote stages. This observation suggests the possible association of LiSIR2RP1 with the cytoskeleton. In order to examine this possibility, attempts were made to isolate the parasite cytoskeleton according to the method described by Schneider et al. [32], that allows subpellicular microtubules and the flagellar axoneme microtubules to be separated from the membrane and cytosolic components by a non-ionic detergent extraction using Triton X-100, followed by centrifugation. The cytoskeleton preparations were then reacted with the antiLiSIR2RP1 antibodies. The results shown in (Fig 4B) suggest that part of LiSIR2RP1 is associated to the cytoskeleton network of both promastigote and amastigote forms. Interestingly, punctuate labelling could also be seen over the flagellar axoneme microtubules when the cytoskeleton preparation was reacted with anti-LiSIR2RP1 antibodies. In agreement with this, the Western blot analysis of the detergent-soluble and insoluble fractions of promastigote and amastigote forms revealed, as expected, the presence of $\alpha$-tubulin in the insoluble fraction, and of LiSIR2RP1 distributed in both soluble and insoluble fractions of promastigotes and amastigotes (Fig 4C). Although in the case of the promastigotes the detergent-insoluble fraction contains a band of $\sim 64.6 \mathrm{kD}$ recognized by the anti-LiSIR2RP1 antibodies, its nature is presently unknown. It might be due to non-complete reduction of LiSIR2RP1 present in a molecular complex with other parasite polypeptides. As a control, we have used an antibody to $T$. brucei RAB11 that cross-react with Leishmania homologous protein already used by others to control the cytoskeletons purity preparations of L. major [37]. Indeed, the RAB11 is a protein found on the membrane of endosomes not associated with the cytoskeleton [36]. As shown in Fig 4A, the RAB11 has different cell distribution pattern when compared to tubulin and LiSIR2RP1. Interestingly, no positive signal could be 
seen in immunofluorescence preparations of parasite cytoskeletons reacted with antiRAB11 antibodies (Fig 4B). Moreover, the WB membranes dehybridized and re-probed with anti-RAB11 antibodies showed that the RAB11 protein is present exclusively in the detergent soluble fraction of parasite extracts (Fig 4C), supporting therefore the specificity of the LiSIR2RP1 and $\alpha$-tubulin interaction.

\section{LiSIR2RP1 accumulates in the posterior pole of promastigotes after taxol treatment}

Leishmania is a protozoan parasite characterized by a digenetic life cycle exhibiting a particular range of cell shapes mostly defined by their internal cytoskeleton. The latter is composed mainly of microtubules that are polymers of repeating $\alpha / \beta$ tubulin heterodimers, and a variety of minor components known as microtubule-associated proteins. The microtubules play an important role in many cellular processes such as mitosis, cell shape, motility, intracellular vesicle transport and organelle position. Several compounds have been described as microtubule-interacting agents, based on their ability to induce or inhibit the tubulin assembly in microtubules. Even though a high degree of tubulin amino acid conservation is found throughout the evolution, there are some reports suggesting that colchicine and benzimidazoles, two classical mammalian tubulin inhibitors, had only a slight effect on the trypanosomatids tubulin polymerization $[38,39]$. On the other hand, taxol, a microtubule network stabilizing agent, affects the parasite cytoskeleton in a dose-dependent manner [40]. The Leishmania parasites were treated for 16 hours with $1 \mu \mathrm{M}$ of the microtubule stabilizing agent, taxol, or with $5 \mu \mathrm{g} / \mathrm{ml}$ of the microtubule network disrupting agent, nocodazole, to analyze if the SIR2RP1 cell distribution is affected by changes in the parasite cytoskeleton. Treatment of promastigotes with taxol led to a weak but distinguishable accumulation of SIR2RP1 in the posterior pole of the cell (Fig. 5A). The treatment of parasites with nocodazole modifies the tubulin distribution, being mainly localized near the nucleus in the parasite body. However, LiSIR2RP1 showed no particular modification in terms of cell distribution, compared to non-treated cells. Although the morphology of treated parasites differed from non-treated ones, their viability measured by propidium iodide (PI) incorporation and flow cytometry analysis revealed no differences. Indeed, after $16 \mathrm{hr}$ of treatment with $1 \mu \mathrm{M}$ taxol or $5 \mu \mathrm{g} / \mathrm{ml}$ nocodazole, the percentage of PI negative parasites \pm standard deviation was $98.2 \pm 0.1$ and $97.6 \pm 0.2 \%$ respectively, compared to $97.4 \pm 0.1 \%$ for untreated ones. Interestingly, after taxol treatment, acetylated $\alpha$-tubulin accumulated in the posterior pole of the cell (Fig. 5B), coinciding with the high LiSIR2RP1 reactive zone seen in panel A. Moreover, punctuate labelling could be seen on the whole periphery of the parasites as well as the flagellum. These observations are in agreement with the notion of LiSIR2RP1 and tubulin being interacting proteins.

\section{LiSIR2RP1 deacetylates $\alpha$-tubulin}

In most eukaryotes, tubulin is subject to several post-translational modifications, including detyrosination, acetylation, phosphorylation, palmitoylation, polyglutamylation and polyglycylation [41]. Tubulin acetylation occurs on lysine-40 of the $\alpha$-tubulin subunit [42]. To test LiSIR2RP1's ability to deacetylate $\alpha$-tubulin in vitro, several amounts of rLiSIR2RP1 were incubated with purified tubulin in the presence or absence of $\mathrm{NAD}^{+}$. The deacetylation of $\alpha$-tubulin was analyzed by Western blot with specific antibodies to either total $\alpha$-tubulin or its acetylated form. As shown in Fig.6, panel A, incubation of a defined amount of tubulin $(0.5 \mu \mathrm{g})$ with increasing quantities of rLiSIR2RP1 $(0.125$ to $0.5 \mu \mathrm{g})$ led to a dose-dependent deacetylation of $\alpha$-tubulin. 
Interestingly, the addition of increasing concentrations of nicotinamide, a known physiological inhibitor of SIR2 deacetylases, led to significant inhibition of tubulin deacetylation by rLiSIR2RP1.

We further explored whether LiSIR2RP1 is able to deacetylate tubulin present within polymerized microtubules. Thus, addition of taxol and GTP to tubulin heterodimers led to microtubule polymerization. Under these conditions, LiSIR2RP1 still had the capacity to efficiently deacetylate tubulin. Moreover, the addition of increasing concentrations of nicotinamide in the assay samples led to the inhibition of LiSIR2RP1mediated tubulin deacetylation (Fig. 6, panel B).

We then examined whether this activity also occurred when using taxol and GTPtreated parasite extracts as a source of polymerized tubulin. As shown in Fig.6, panels C-D, when total extracts from promastigotes and amastigotes treated with taxol were used as a source of polymerized microtubules, LiSIR2RP1 was also able to deacetylate tubulin. Taken together, these observations demonstrate that tubulin is a substrate of LiSIR2RP1 deacetylase.

We further examined the LiSIR2RP1 $\mathrm{NAD}^{+}$-dependent deacetylase substrate's specificity by using acetylated BSA or cytochrome c and Western blot technique. In contrast to tubulin, the level of BSA and cytochrome $\mathrm{c}$ acetylation presented no changes after incubation with LiSIR2RP1 in the presence or absence of NAD ${ }^{+}$. This allows us to conclude that, at least from the approach we have used, LiSIR2RP1 does not deacetylate either BSA or cytochrome c, suggesting some substrate specificity of LiSIR2RP1 as a deacetylase (data not shown).

In order to evaluate whether LiSIR2RP1 is deacetylating tubulin in vivo, we have analyzed the ratio of acetylated tubulin over total $\alpha$-tubulin in the wild type and single LiSIR2RP1 knockout promastigotes and axenic amastigotes. Only a slight difference in the level of tubulin acetylation between the wild type and single knockout axenic amastigotes was detected (Fig. 6, panel E). However, the disruption of a single allele from the LiSIR2RP1 gene may not be enough to affect the tubulin acetylation level, even though it is enough to reduce amastigotes ability to multiply, be it in vitro as free forms or inside macrophages, or in vivo in Balb/c mice [30]. 


\section{DISCUSSION}

In this report, we describe and characterize the enzymatic activities of the LiSIR2RP1 for the first time. Assuming that this protein is involved in the parasite's virulence and survival, it could constitute a new and potential drug target against leishmaniasis that needs to be exploited. We have demonstrated that, although LiSIR2RP1 differs from its T. brucei ortholog, TbSIR2RP1 [22] in terms of subcellular localization (cytosolic versus nuclear), it expresses similar enzymatic activities, being able to act as an $\mathrm{NAD}^{+}$dependent deacetylase and to transfer $\left[{ }^{32} \mathrm{P}\right] \mathrm{NAD}^{+}$to histones and, to a lesser extent, to BSA or tubulin. Initial reports on the yeast SIR2 have shown that the protein has a weak mono-ADP-ribosyltransferase activity and a more robust $\mathrm{NAD}^{+}$-dependent deacetylase activity [21]. This finding led to the general idea that the ADP-ribosyltransferase activity might be the result of a non-enzymatic reaction. However, our data and the investigations using TbSIR2RP1 [22], the human SIRT6 [23] or the P. falciparum Sir2 [24], provided evidence supporting the notion that these SIR2 family members could mediate the enzymatic transfer of the ADP-ribosyl group. Studies from Kowieski et al. [43] have recently shed light on the ADP-ribosylation mechanism catalyzed by the TbSIR2RP1. The authors demonstrated that ADP-ribosylation of histone by TbSIR2RP1 required an acetylated substrate. Additionally, two distinct ADPribosylation pathways that involve an acetylated substrate, $\mathrm{NAD}^{+}$and TbSIR2RP1, were described. One is a non-catalytic reaction between the deacetylation product o-acetylADP-ribose (or its hydrolysis product, ADPr) and histones, and the other a more efficient mechanism involving interception of an ADP-ribose-acetylpeptide-enzyme intermediate by a side-chain nucleophile from bound histone [43] This might also explain the low level of tubulin ADP-ribosylation catalyzed by the Leishmania SIR2 protein. If the enzyme preferentially deacetylates tubulin and the ADP-ribosylation requires an acetylated protein, the occurrence of the latter will be dependent on the first one [43].

The LiSIR2RP1 possesses the expected $\mathrm{NAD}^{+}$-dependent deacetylase activity that characterizes the SIR2 family members, and one of their reaction products, nicotinamide, is an $\mathrm{NAD}^{+}$non-competitive inhibitor. Several biological activities have been attributed to the proteins belonging to the SIR2 family, that, even though sharing a conserved enzymatic core domain, are flanked at their $\mathrm{N}$ - and $\mathrm{C}$-terminal parts by divergent sequences between family members, which may promote the binding to specific substrates [44]. Two main Sirtuin substrates that have been identified are large fibrous macromolecular complexes, chromatin and tubulin [15]. The partial colocalization of $L$. infantum SIR2RP1 with $\alpha$-tubulin and its association with the parasite cytoskeleton, suggested that tubulin could be a substrate of this enzyme as it is for the human enzymes SIRT2 and HDAC6 $[15,34]$. Control tests using antibodies to a parasite cytosolic protein, RAB11, which confirmed the absence of RAB11-tubulin relationship, strongly support the notion of LiSIR2RP1-tubulin specific interaction. In fact, LiSIR2RP1 was either able to deacetylate tubulin in dimers or, when present, in taxol stabilized microtubules, or in total promastigote or amastigote extracts. Although the $\alpha$-tubulin acetylation was already reported a few years ago, its importance in cell biological processes is not yet completely understood. The presence of acetylated tubulin in stable microtubules and the absence of highly acetylated microtubules in the fibroblast leading edge, that is a dynamic structure involved in cell motility, suggested that this post-translational modification could play a role in microtubule stability [45]. However, Palazzo et al., [46] demonstrated that enhanced tubulin acetylation does not increase the level of stable microtubules. Moreover, ciliated or flagellated protists can use a nonacetylable $\alpha$-tubulin with no observable ill effects on the microtubules or the 
organisms [47]. By contrast, the level of tubulin acetylation seems to affect a number of cellular events that includes the infection of $\mathrm{CD}^{+} \mathrm{T}$ cells by HIV1 [48], the binding and transport of a kinesin 1 [49], the correct organization of the immune synapse [50], and the dynamics of cellular adhesions [51]. Interestingly, the promastigotes treatment with the microtubule stabilizing agent, taxol, increased the number of parasites showing an accumulation of LiSIR2RP1 in the posterior pole of the cell that is enriched in acetylated $\alpha$-tubulin. It is likely that LiSIR2RP1 could bind to $\alpha$-tubulin and just deacetylate it in a specific step during the parasite's life cycle. Additionally, the promastigotes infect macrophages through a receptor-mediated mechanism initiated at the posterior pole of the parasite [52]. One can hypothesize that the accumulation of LiSIR2RP1 in the posterior pole could be important to the contact site with the APC during the infection. Indeed, translocation and accumulation of HDAC 6, a human cytosolic deacetylase, in the immune synapse at the contact site of T cells with APC has recently been reported [50]. Furthermore, it is noteworthy that the influence of the deacetylase activity in the cell motility versus adhesion reported by Tran et al. [51] could also be relevant to the parasites when they are infecting the host cell.

The Leishmania parasites are subject to several modifications in their morphology during their complex life cycle. Although some environmental factors, such as $\mathrm{pH}$, temperature and nutrients, can trigger morphological changes in the parasite, relatively little is known about the molecular processes that mediate the cellular remodelling. Further functional studies of LiSIR2RP1 could help disclose the role of the tubulin acetylation/deacetylation and/or ADP-ribosylation in the remodelling of the parasite's morphology and the infection of host cells. 


\section{ACKNOWLEDGEMENTS}

This work has been funded by Fundação para a Ciência e Tecnologia (FCT) POCI 2010, co-funded by FEDER grant number POCI/SAU- FCF/59837/2004, Centre Franco Indien pour la promotion de la recherche avancée; Indo-French Centre for the promotion of advanced research CEFIPRA/IFCPAR grant number 3603, INSERM and IRD UR 008. JT is supported by a fellowship from FCT number SFRH/BD/18137/2004; NS has a fellowship in the above-mentioned FCT/FEDER project. The authors thank I. Silveira for her support in the radioactive experiments, A. Tomás for providing the LicTXNPx bacterial clone, Professor Field M.C. for the gift of the antibodies to TbRAB11, and A. Ferreira for the English revision of the manuscript. 


\section{REFERENCES}

1 Brachmann, C.B., Sherman, J.M., Devine, S.E., Cameron, E.E., Pillus, L. and Boeke, J.D. (1995) The SIR2 gene family, conserved from bacteria to humans, functions in silencing, cell cycle progression, and chromosome stability. Genes Dev. 9, 2888-2902

2 Bryk, M., Banerjee, M., Murphy, M., Knudsen, K.E., Garfinkel, D.J. and Curcio, M.J. (1997) Transcriptional silencing of Ty1 elements in the RDN1 locus of yeast. Genes Dev. 11, 255-269

3 Smith, J.S. and Boeke, J.D. (1997) An unusual form of transcriptional silencing in yeast ribosomal DNA. Genes Dev. 11, 241-254

4 Imai, S., Armstrong, C.M., Kaeberlein, M. and Guarente, L. (2000) Transcriptional silencing and longevity protein Sir2 is an NAD-dependent histone deacetylase. Nature 403, 795-800

5 Blander, G. and Guarente. (2004). The Sir2 family of protein deacetylases. Annu. Rev. Biochem. 73, 417-435

6 Zemzoumi, K., Sereno, D., Francois, C., Guilvard, E., Lemesre, J.L., Ouaissi, A. (1998) Leishmania major: cell type dependent distribution of a $43 \mathrm{kDa}$ antigen related to silent information regulatory-2 protein family. Biol. Cell 90, 239-245

7 Frye, RA. (1999) Characterization of five human cDNAs with homology to the yeast SIR2 gene: Sir2-like proteins (sirtuins) metabolize NAD and may have protein ADP-ribosyltransferase activity. Biochem. Biophys. Res. Commun. 260, 273-279

8 Frye RA. (2000) Phylogenetic classification of prokaryotic and eukaryotic Sir2-like proteins. Biochem. Biophys. Res, Commun. 273, 793-798

9 Mostoslavsky, R., Chua, K.F., Lombard, D.B., Pang, W.W, Fischer, M.R., Gellon, L. et al. (2006) Genomic instability and aging-like phenotype in the absence of the of mammalian SIRT6. Cell 124, 315-329

10 Haigis, M.C., Mostoslavsky, R., Haigis, K.M., Fahie, K., Christodoulou, D.C., Murphy et al. (2006) SIRT4 inhibits glutamate dehydrogenase and opposes the effects of calorie restriction in pancreatic beta cells. Cell 126, 941-954

11 Vaziri, H., Dessain, S.K., Ng Eaton, E., Imai, S.I., Frye, R.A., Pandita, T.K., Guarente, L. and Weinberg, R.A. (2001) hSIR2 (SIRT1) functions as an NADdependent $\mathrm{p} 53$ deacetylase. Cell 107, 149-59

12 Luo, J., Nikolaev, A.Y., Imai, S., Chen, D., Su, F., Shiloh, A., Guarente, L. and Gu, W. (2001) Negative control of p53 by Sir2alpha promotes cell survival under stress. Cell 107, 137-148

13 Muth, V., Nadaud, S., Grummt, I., Voit, R. (2001) Acetylation of TAF(I)68, a subunit of TIF-IB/SL1, activates RNA polymerase I transcription. EMBO J. 20, $1353-1362$

14 Fulco, M., Schiltz, R.L., Iezzi, S., King, M.T., Zhao, P., Kashiwaya, Y., Hoffman, E., Veech, R.L. and Sartorelli, V. (2003) Sir2 regulates skeletal muscle differentiation as a potential sensor of the redox state. Mol. Cell 12, 51-62

15 North, B.J., Marshall, B.L., Borra, M.T., Denu, J.M. and Verdin, E. (2003) The human Sir2 ortholog, SIRT2, is an NAD+-dependent tubulin deacetylase. Mol. Cell. 11, 437-444

16 Dryden, S.C., Nahhas, F.A., Nowak, J.E., Goustin, A.S. and Tainsky MA. (2003) Role for human SIRT2 NAD-dependent deacetylase activity in control of mitotic exit in the cell cycle. Mol. Cell Biol. 23, 3173-3185

17 Vaquero, A., Scher, M.B., Lee, D.H., Sutton, A., Cheng, H.L., Serrano, L., Sternglanz, R. and Reinberg D. (2006) SirT2 is a histone deacetylase with preference for histone H4 Lys 16 during mitosis. Genes Dev. 20, 1256-1261 
18 Schwer, B., Bunkenborg, J., Verdin, R.O., Andersen, J.S. and Verdin, E. (2006) Reversible lysine acetylation controls the activity of the mitochondrial enzyme acetyl-CoA synthetase 2. Proc. Natl. Acad. Sci. U SA 103, 10224-10229

19 Tanny, J.C. and Moazed, D. (2001) Coupling of histone deacetylation to NAD breakdown by the yeast silencing protein Sir2: Evidence for acetyl transfer from substrate to an NAD breakdown product. Proc. Natl. Acad. Sci. U SA 98, 415-420

20 Sauve, A.A., Celic, I., Avalos, J., Deng, H., Boeke, J.D. and Schramm, V.L. (2001) Chemistry of gene silencing: the mechanism of NAD+-dependent deacetylation reaction. Biochemistry 40, 15456-15463

21 Tanny, J.C., Dowd, G.J., Huang, J., Hilz, H. and Moazed, D. (1999) An enzymatic activity in the yeast Sir2 protein that is essential for gene silencing. Cell 99, 735-745

22 Garcia-Salcedo, J.A., Gijon, P., Nolan, D.P., Tebabi, P. and Pays, E. (2003) A chromosomal SIR2 homologue with both histone NAD-dependent ADPribosyltransferase and deacetylase activities is involved in DNA repair in Trypanosoma brucei. EMBO J. 22, 5851-5862

23 Liszt, G., Ford, E., Kurtev, M. and Guarente, L. (2005) Mouse Sir2 homolog SIRT6 is a nuclear ADP-ribosyltransferase. J. Biol. Chem. 280, 21313-21320

24 Merrick, C.J. and Duraisingh, MT. (2007) Plasmodium falciparum Sir2: an unusual sirtuin with dual histone deacetylase and ADP-ribosyltransferase activity. Eukaryot. Cell. 6, 2081-2091

25 Tsang, A.W. and Escalante-Semerena, J.C. (1998) CobB, a new member of the SIR2 family of eucaryotic regulatory proteins, is required to compensate for the lack of nicotinate mononucleotide:5,6-dimethylbenzimidazole phosphoribosyltransferase activity in cobT mutants during cobalamin biosynthesis in Salmonella typhimurium LT2. J. Biol. Chem. 273, 31788-31794

26 Tissenbaum, H.A. and Guarente, L. (2001) Increased dosage of a sir-2 gene extends lifespan in Caenorhabditis elegans. Nature 410, 227-230

27 Kaeberlein, M., McVey, M. and Guarente, L. (1999) The SIR2/3/4 complex and SIR2 alone promote longevity in Saccharomyces cerevisiae by two different mechanisms. Genes Dev. 13, 2570-2580

28 Rogina, B. and Helfand, S.L. (2004) Sir2 mediates longevity in the fly through a pathway related to calorie restriction. Proc. Natl. Acad. Sci. U S A 101, 15998156003

29 Vergnes, B., Sereno, D., Madjidian-Sereno, N., Lemesre, J.L. and Ouaissi, A. (2002) Cytoplasmic SIR2 homologue overexpression promotes survival of Leishmania parasites by preventing programmed cell death. Gene 296, 139-50

30 Vergnes, B., Sereno, D., Tavares, J., Cordeiro-da-Silva, A., Vanhille, L., MadjidianSereno, N., Depoix, D. Monte-Alegre, A. and Ouaissi, A. (2005) Targeted disruption of cytosolic SIR2 deacetylase discloses its essential role in Leishmania survival and proliferation. Gene 363, 85-96

31 Freitas-Junior, L.H., Hernandez-Rivas, R., Ralph, S.A., Montiel-Condado, D., Ruvalcaba-Salazar, O.K., Rojas-Meza A.P., Mancio-Silva, L., Leal-Silvestre R.J., Gontijo, A.M., Shorte, S. and Scherf, A. (2005) Telomeric heterochromatin propagation and histone acetylation control mutually exclusive expression of antigenic variation genes in malaria parasites. Cell 121, 25-36

32 Schneider, A., Sherwin, T., Russell, D.G., Gull, K. and Seebeck, T. (1987) Subpellicular and flagellar microtubules of Trypanosoma brucei brucei contain the same alpha tubulin isoforms. J. Cell Biol. 104, 431-438 
33 Scaife RM, Wilson L, Purich DL. (1992) Microtubule protein ADP-ribosylation in vitro leads to assembly inhibition and rapid depolymerization. Biochemistry 31, 310-316

34 Hubbert, C., Guardiola, A., Shao, R., Kawaguchi, Y., Ito, A., Nixon, A., Yoshida, M., Wang, X.F. and Yao, T.P. (2002) HDAC6 is a microtubule-associated deacetylase. Nature 417, 455-458

35 Kouzarides, T. (2000) Acetylation: a regulatory modification to rival phosphorylation? EMBO J. 19, 1176-1179

36 Ambit, A., Fasel, N., Coombs, G.H., Mottram, J.C. (2008) An essential role for the Leishmania major metacaspase in cell cycle progression. Cell Death. Differ. 15, 113-22

37 Jeffries, T.R., Morgan, G.W., Field, M.C. (2001) A developmentally regulated rab11 homologue in Trypanosoma brucei is involved in recycling processes. J. Cell Sci. 114, 2617-26

38 MacRae, T.H. and Gull, K. (1990) Purification and assembly in vitro of tubulin from Trypanosoma brucei brucei. Biochem. J. 265, 87-93

39 Vickerman, K. and Preston, T.M. (1970) Spindle microtubules in the dividing nuclei of trypanosomes. J. Cell Sci. 6, 365-383

40 Baum, S.G., Wittner, M., Nadler, J.P., Horwitz, S.B., Dennis, J.E., Schiff, P.B. and Tanowitz, H.B. (1981) Taxol, a microtubule stabilizing agent, blocks the replication of Trypanosoma cruzi. Proc. Natl. Acad. Sci. U S A 78, 4571-4575

41 Rosenbaum, J. (2000) Cytoskeleton: Functions for tubulin modifications at last. Current Biology 10, 801-803

42 Nogales, E., Whittaker, M., Milligan, R.A. and Downing, K.H. (1999) Highresolution model of the microtubule. Cell 96, 79-88

43 Kowieski, T.M., Lee, S., Denu, J.M. (2008) Acetylation-dependent ADPribosylation by Trypanosoma brucei Sir2. J. Biol. Chem. 283, 5317-5326

44 Cuperus, G., Shafaatian, R. and Shore, D. (2000) Locus specificity determinants in the multifunctional yeast silencing protein Sir2. EMBO J. 19, 2641-2651

45 Wadsworth, P. (1999) Regional regulation of microtubule dynamics in polarized, motile cells. Cell Motil. Cytoskeleton 42, 48-59

46 Palazzo, A., Ackerman, B. and Gundersen, G.G. (2003) Cell biology: Tubulin acetylation and cell motility. Nature 16, 230

47 Gaertig, J., Cruz, M.A., Bowen, J., Gu, L., Pennock, D.G. and Gorovsky MA. (1995) Acetylation of lysine 40 in alpha-tubulin is not essential in Tetrahymena thermophila. J. Cell Biol. 129, 1301-1310

48 Valenzuela-Fernandez, A., Alvarez, S., Gordon-Alonso, M., Barrero, M., Ursa, A., Cabrero, J.R., Fernandez, G., Naranjo-Suarez, S., Yanez-Mo, M., Serrador, J.M., Munoz-Fernandez, M.A. and Sanchez-Madrid, F. (2005) Histone deacetylase 6 regulates human immunodeficiency virus type 1 infection. Mol. Biol. Cell 11, 54455454.

49 Reed, N.A., Cai, D., Blasius, T.L., Jih, G.T., Meyhofer, E., Gaertig, J. and Verhey, K.J. (2006) Microtubule acetylation promotes kinesin-1 binding and transport. Curr. Biol. 16, 2166-2172

50 Serrador, J.M., Cabrero, J.R., Sancho, D., Mittelbrunn, M., Urzainqui, A. and Sanchez-Madrid, F. (2004) HDAC6 deacetylase activity links the tubulin cytoskeleton with immune synapse organization. Immunity 20, 417-428

51 Tran, A.D., Marmo, T.P., Salam, A.A., Che, S., Finkelstein, E., Kabarriti, R., Xenias, H.S., Mazitschek, R., Hubbert, C., Kawaguchi, Y., Sheetz, M.P., Yao, T.P. 
and Bulinski, J.C. (2007) HDAC6 deacetylation of tubulin modulates dynamics of cellular adhesions. J. Cell. Sci. 120, 1469-1479

52 Courret, N., Frehel, C., Gouhier, N., Pouchelet, M., Prina, E., Roux, P. and Antoine, J.C. (2002) Biogenesis of Leishmania-harbouring parasitophorous vacuoles following phagocytosis of the metacyclic promastigote or amastigote stages of the parasites. J. Cell Sci. 111, 2303-2316 


\section{FIGURE LEGENDS}

Figure 1 LiSIR2RP1 characterization. The purity of the rLiSIR2RP1 was confirmed by SDS-PAGE Coomassie blue staining (A, lane 1). A monoclonal antibody IIIG4 to $L$. major recombinant SIR2RP1 showed strong positive signals when reacted in Western blot against rLiSIR2RP1 (A, lane 2). Western blot analysis of LiSI2RP1 expression in total parasite extracts $(\mathrm{B}, \mathrm{Pl}$-logarithmic promastigotes; Ps-stationary promastigotes and A-amastigotes) evidenced by using a mouse polyclonal antibody raised against the rLiSIR2RP1. Samples of protein extracts from each parasite developmental stage also reacted with anti- $\alpha$-tubulin monoclonal antibody, DM1A.

Figure 2 LiSIR2RP1 is a $\mathrm{NAD}^{+}$-dependent deacetylase. The $\mathrm{NAD}^{+}$-dependent deacetylase activity was measured using a fluorometric deacetylase kit (CycLex SIRT1/Sir2 fluorometric assay kit) in the presence of $0.25 \mu \mathrm{g}$ of rLiSIR2RP1. LiSIR2RP1 is an NAD ${ }^{+}$-dependent deacetylase that is not inhibited by $1 \mu \mathrm{M}$ of TSA (A). The rate of the deacetylase reaction was measured in the presence of several $\mathrm{NAD}^{+}$ concentrations (B). Nicotinamide, a deacetylase reaction product, inhibited the LiSIR2RP1 NAD ${ }^{+}$-dependent deacetylase activity in a dose-dependent manner (C) and according to the Lineweaver-Burk plot, $50 \mu \mathrm{M}$ of nicotinamide promotes an $\mathrm{NAD}^{+}$noncompetitive inhibition (D). The results are expressed as the mean rate of reaction \pm standard deviation for the first 20 minutes.

Figure 3 LiSIR2RP1 has ADP-ribosyltransferase activity. (A)The rLiSIR2RP1 ( ) ADP-ribosyltransferase activity was assessed using $\left[{ }^{32} \mathrm{P}\right] \mathrm{NAD}$ as donor and BSA $(*)$ or calf thymus histones (\#) as acceptor proteins. A non-related Leishmania recombinant protein, rLicTXNPx1 $(\rightarrow)$, was included as controls. The reaction products were analyzed by SDS-PAGE Coomassie blue stained and by autoradiography. (B) Quantitative analysis of the effect of $\mathrm{NAD}^{+}$, acceptor protein or rLiSIR2RP1 amount on the ribosylation reaction. The reaction products were precipitated with TCA, collected, washed and then counted after the addition of scintillation liquid. (C) Assessment of tubulin (-) ADP-ribosylation mediated by rLiSIR2RP1. Tubulin and histones were included as acceptor proteins, ${ }^{32} \mathrm{P}[\mathrm{NAD}]$ as donor and rLiTXNPx as control. The reaction products were analyzed by SDS-PAGE Coomassie blue staining and by autoradiography.

Figure 4 Cellular distributions of LiSIR2RP1 and $\boldsymbol{\alpha}$-tubulin. The L. infantum promastigotes and axenic amastigotes (A) and their respective cytoskeletons (B) were double stained by immunofluorescence with mouse anti-LiSIR2RP1 antibodies and rabbit anti- $\alpha$-tubulin antibodies (left panels) or with rabbit anti-TbRAB11 antibodies and mouse anti- $\alpha$-tubulin antibodies followed by their respectives Alexa Fluor 488 (green) or Alexa Fluor 568 (red) conjugated IgG and counterstained with DAPI (blue). The parasites were visualized under a 1000x magnification using a Zeiss Axio Imager Z1 microscope, and Z-series optical sections were collected using an AxioCam. Data stacks were deconvolved using either the Axiovision AxioVs40 V 4.2.0.0 (Carl Zeiss) or the Huygens Essential version 3.0.2p1. Western blot analysis of Triton X-100 extracted $L$. infantum promastigote $(\mathrm{P})$ and amastigote (A) fractions. $\mathrm{S}$ designates the supernatant and I the cytoskeleton pellet. The fractions were separated in a 10\% SDSPAGE, transferred to a nitrocellulose membrane and probed with either anti- $\alpha$-tubulin, anti-acetylated tubulin, anti-LiSIR2RP1or anti-TbRAB11 antibodies (C). 
Figure 5 Cellular distribution of LiSIR2RP1, $\alpha$-tubulin and acetylated $\alpha$-tubulin after parasite treatment with taxol or nocodazole.

The cellular distribution of the LiSIR2RP1, $\alpha$-tubulin and acetylated $\alpha$-tubulin were analyzed after 16 hours of $L$. infantum promastigote treatment with $1 \mu \mathrm{M}$ of taxol or $5 \mu \mathrm{g} / \mathrm{ml}$ of nocodazole at $27^{\circ} \mathrm{C}$. The parasites were fixed with paraformaldehyde, made permeable with triton X-100 and double labelled with mouse anti-LiSIR2RP1 antibodies and rabbit anti- $\alpha$-tubulin antibodies (A) or with mouse anti-acetylated $\alpha$ tubulin antibodies (6-11B-1) and rabbit anti- $\alpha$-tubulin antibodies (B) followed by their respectives Alexa Fluor 488 (green) or Alexa Fluor 568 (red) conjugated IgG and counterstained with DAPI (blue). The parasites were visualized under a 1000x magnification using a Zeiss Axio Imager Z1 microscope, and Z-series optical sections were collected using an AxioCam. Data stacks were deconvolved using either the Axiovision AxioVs40 V 4.2.0.0 (Carl Zeiss) or the Huygens Essential version 3,0.2p1.

Figure $6 \alpha$-Tubulin is deacetylated by LiSIR2RP1. Purified tubulin dimers (A), taxol stabilized microtubules (B), taxol stabilized microtubules from whole promastigote lysate (C) and taxol stabilized microtubules from whole amastigote lysate (D) were incubated with several amounts of purified rLiSIR2RP1 in the presence or absence of $1 \mathrm{mM}$ of $\mathrm{NAD}^{+}$and several nicotinamide concentrations for 3 hours at room temperature. The reaction products were analyzed by western blotting with specific antibodies to acetylated $\alpha$-tubulin, $\alpha$-tubulin and LiSIR2RP1. Analysis by Western blot of the acetylated $\alpha$-tubulin and total $\alpha$-tubulin levels in the wt and LiSIR2+/- mutant (clone N2) promastigote (P) and axenic amastigote (A) total extracts (E). 
A

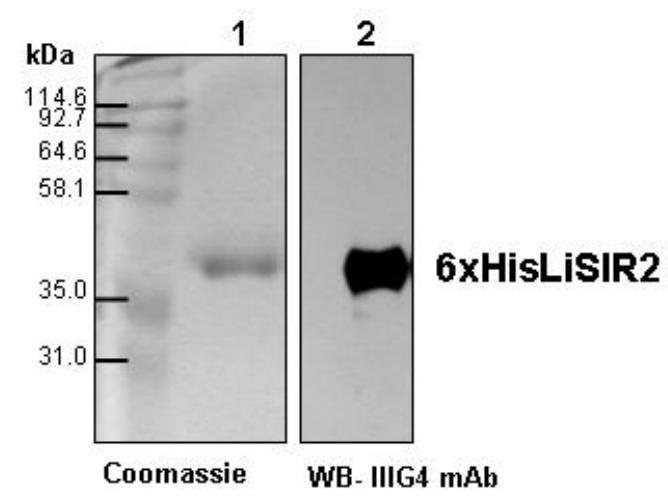

B

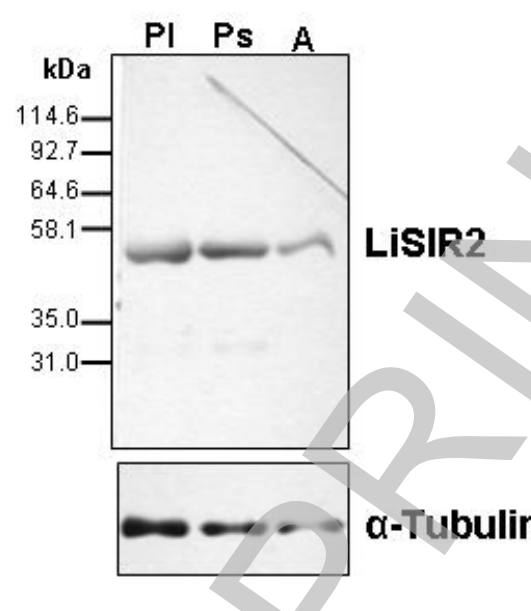

Figure 1 

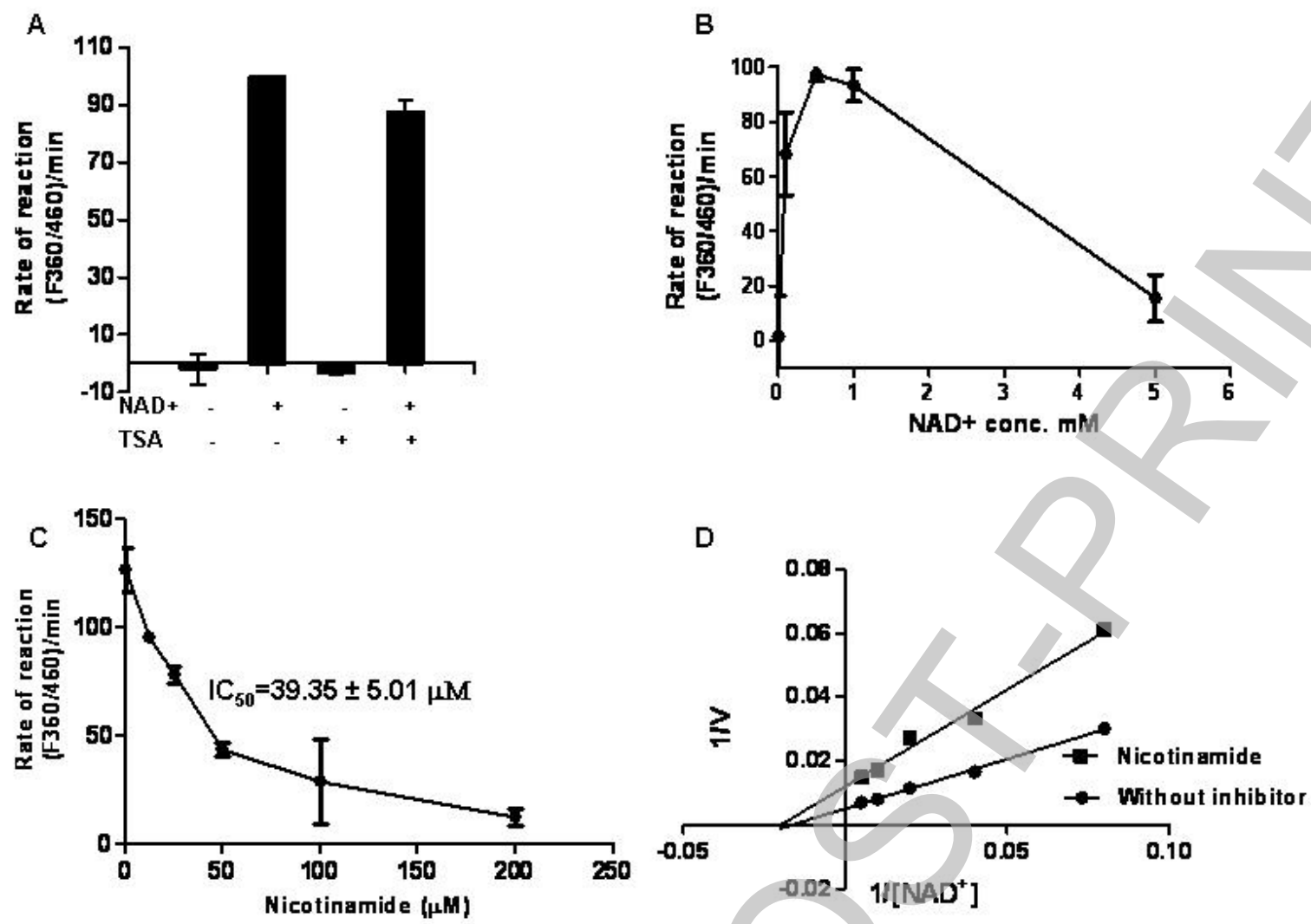

Figure 2

Licenced copy. Copying is not permitted, except with prior permission and as allowed by law. (C) 2008 The Authors Journal compilation (C) 2008 Biochemical Society 
A
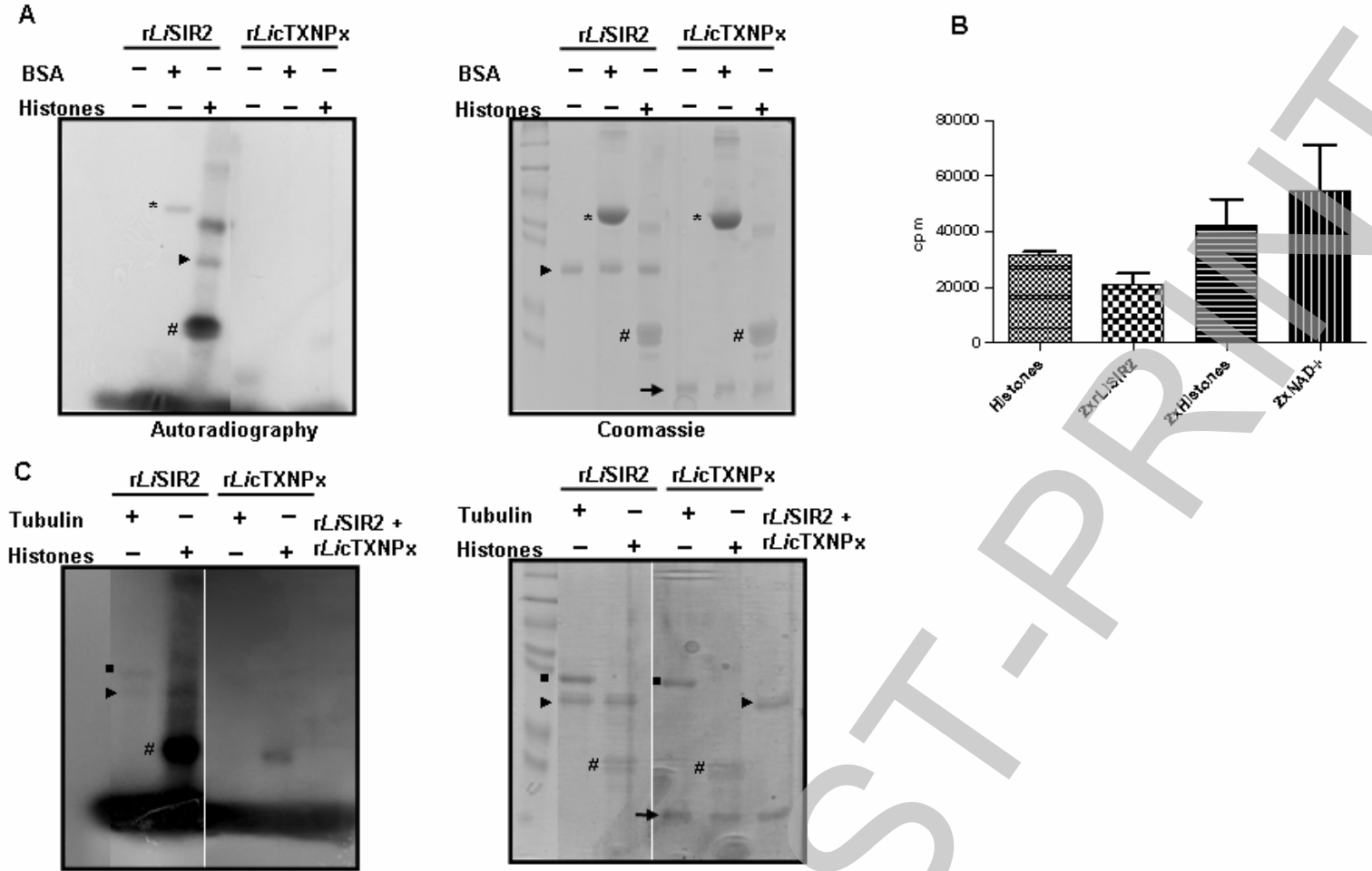

Auto radiography

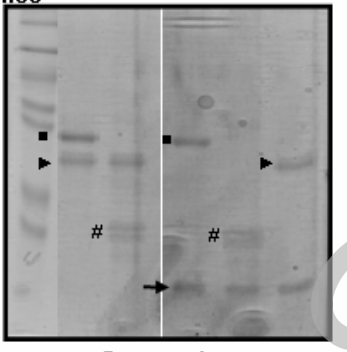

Coomassie

Figure 3

Licenced copy. Copying is not permitted, except with prior permission and as allowed by law. (C) 2008 The Authors Journal compilation (c) 2008 Biochemical Society 
B Biochemical Journal Immediate Publication. Published on 03 Jul 2008 as manuscript BJ20080666

A

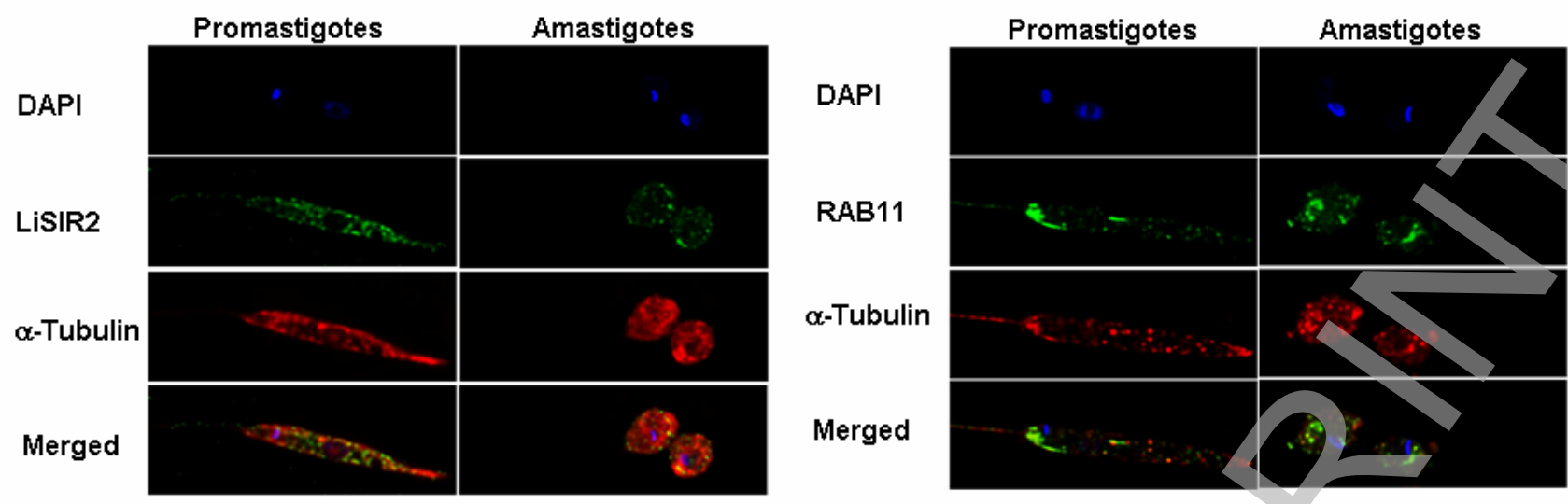

B
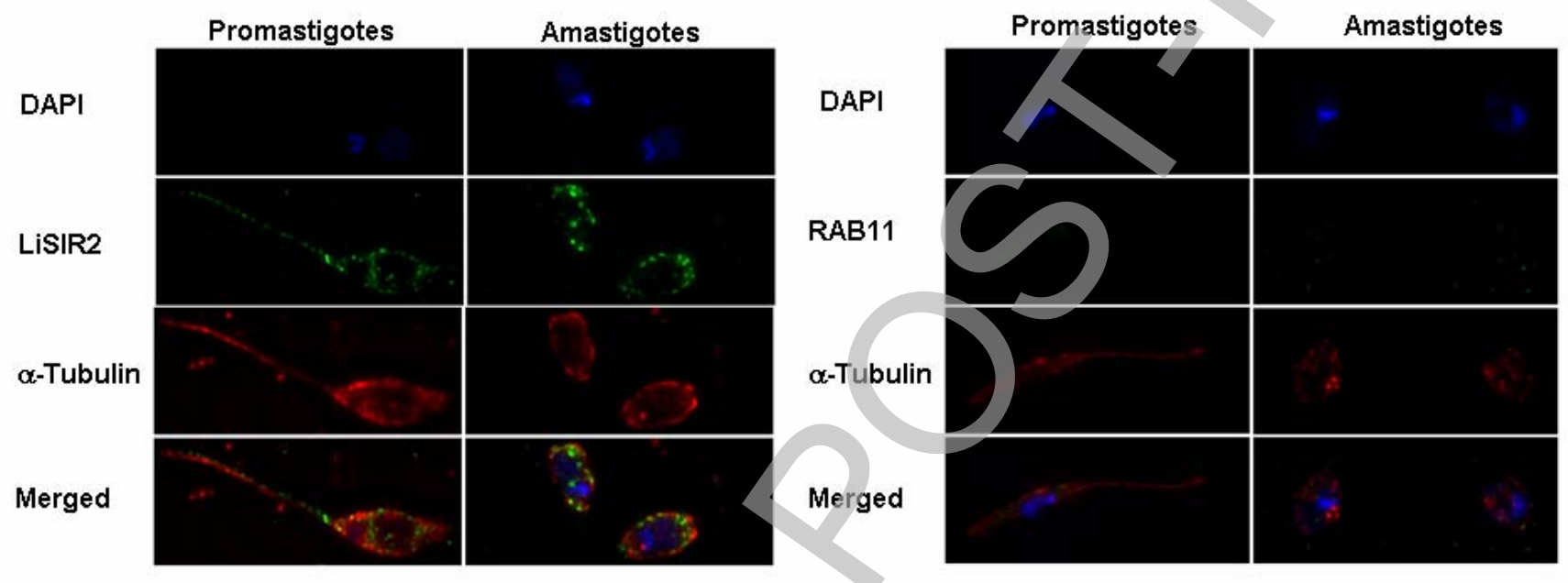

C

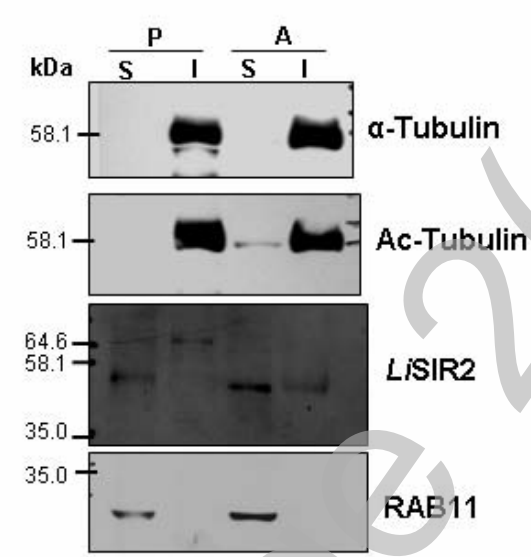

Figure 4

Licenced copy. Copying is not permitted, except with prior permission and as allowed by law. (C) 2008 The Authors Journal compilation (C) 2008 Biochemical Society 
Biochemical Journal Immediate Publication. Published on 03 Jul 2008 as manuscript BJ20080666

A

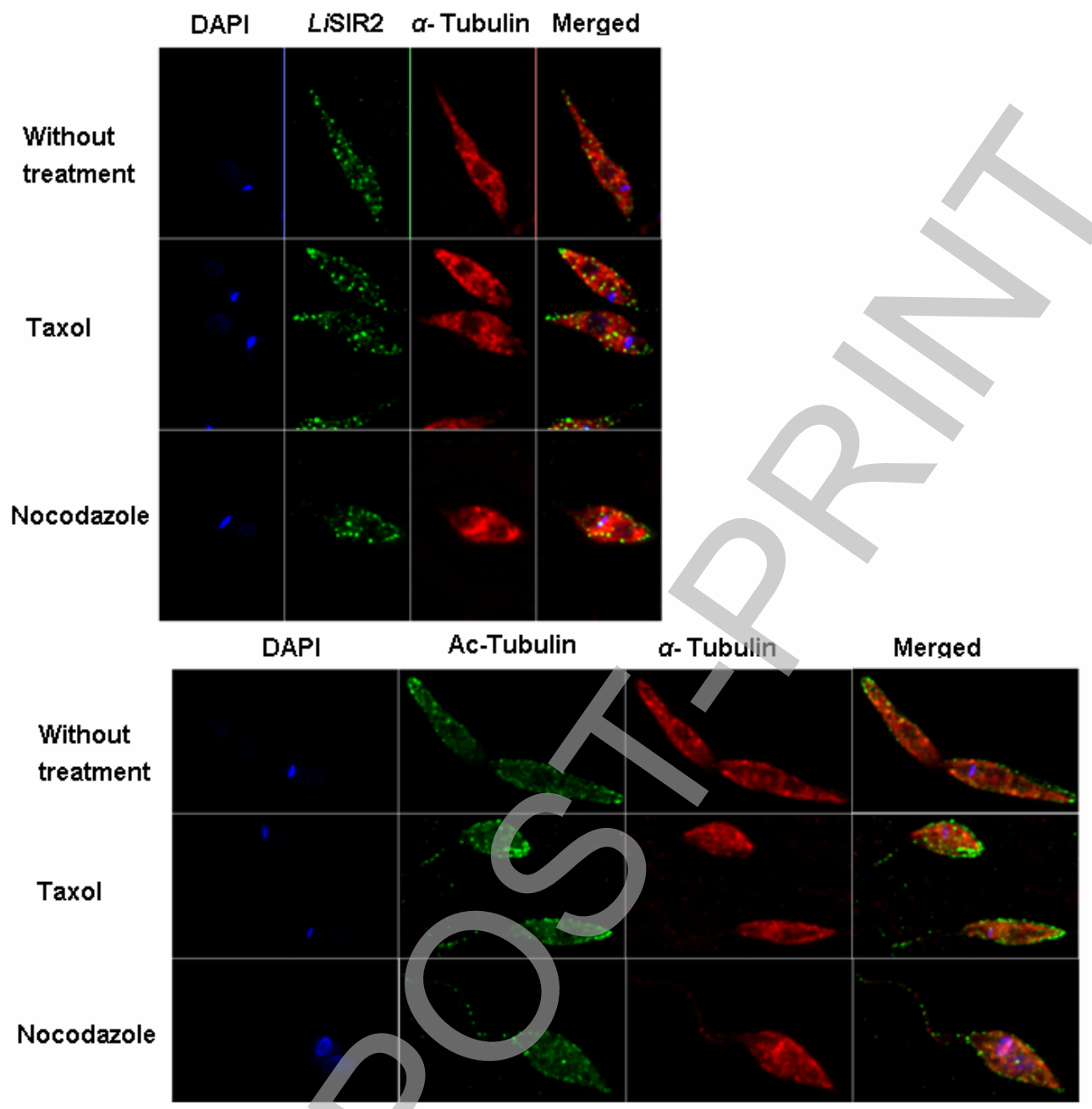

B

Figure 5

Licenced copy. Copying is not permitted, except with prior permission and as allowed by law. (C) 2008 The Authors Journal compilation (C) 2008 Biochemical Society 
A

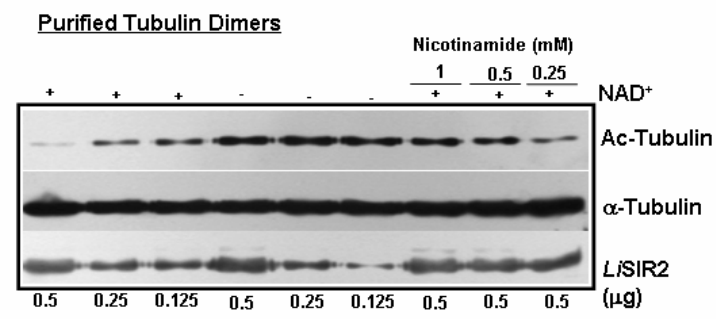

B

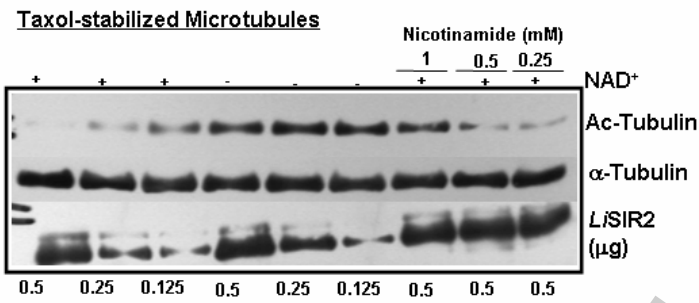

$\mathrm{C}$

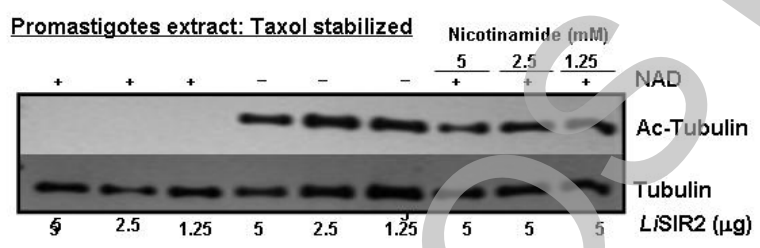

$\mathrm{D}$

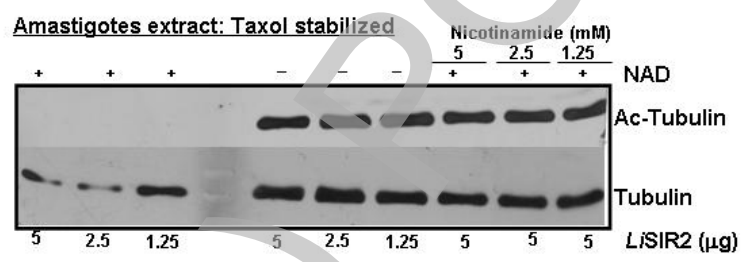

Figure 6

Licenced copy. Copying is not permitted, except with prior permission and as allowed by law. (C) 2008 The Authors Journal compilation (C) 2008 Biochemical Society 
E
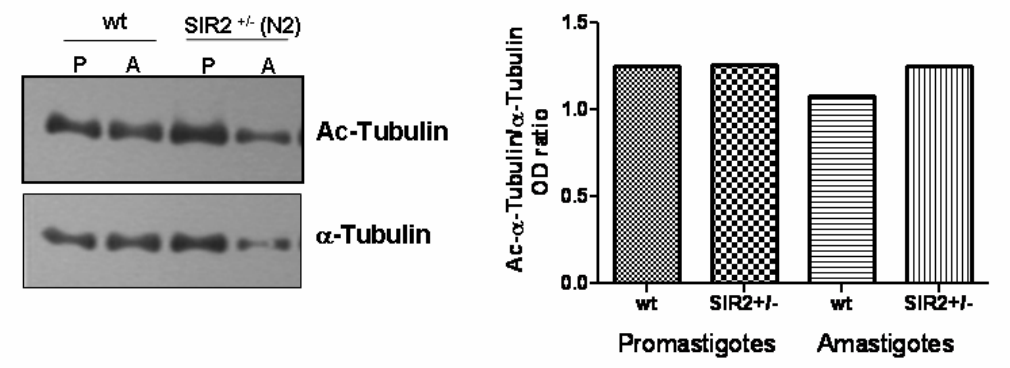

Figure 6 